\title{
Blood Pressure Management in Acute Stroke: Comparison of Current Guidelines with Prescribing Patterns
}

\author{
Salmann Kanji, Céline Corman, Andre G. Douen
}

\begin{abstract}
Objective: Current recommendations for treating elevated blood pressure (BP) in the acute stroke are based largely on expert opinion and vary with regard to treatment thresholds and choice of antihypertensive agents. In this study we investigate the influence of these recommendations by comparing the management of hypertension in acute stroke at a tertiary care hospital with current guidelines. Method: Retrospective chart review of patients admitted with acute stroke at The Ottawa Hospital-General Campus over six consecutive months. The use of antihypertensive medications (type, dose, routes of administration, BP recordings) in the first seven days after admission was noted. Results: Transdermal nitroglycerin paste was the most commonly used antihypertensive agent. In contrast to the $15 \%$ reduction in BP over 24 hours recommended for lowering BP in hypertensive patients with ischemic stroke, nitroglycerin caused a $>15 \%$ reduction of BPover the first 24 hours on $60 \%$ of the occasions used. Furthermore, despite concerns about sublingual nifedipine, this was the second most commonly prescribed agent. Surprisingly, the mean time to first BP measurement following initiation of antihypertensive therapy was $117 \pm 43$ minutes in ischemic stroke and $88 \pm 89$ minutes in hemorrhagic strokes. Conclusions: The current guidelines for management of acute poststroke hypertension appear to have little influence on prescribing patterns, leading to considerable variations in practice. Such variations, likely due to uncertainty caused by lack of evidence from randomised controlled trials, are intolerable as patients maybe submitted to nonstandardised, potentially harmful care such as inappropriate choice of antihypertensives and inadequate BP monitoring as observed in this study.
\end{abstract}

RÉSUMÉ: La prise en charge de la tension artérielle dans le traitement de l'accident vasculaire cérébral aigu: comparaison des lignes directrices actuelles et des modes de prescription. Objectif: Les recommandations en vigueur pour le traitement de l'hypertension artérielle (HTA) dans l'accident vasculaire cérébral aigu (AVCA) sont basées en grande partie sur l'opinion d'experts et varient quant aux niveaux où un traitement est indiqué et au choix d'agents antihypertenseurs. Dans cette étude, nous évaluons l'influence de ces recommandations sur la pratique en comparant la prise en charge de l'hypertension dans l'AVCAdans un hôpital de soins tertiaires et les lignes directrices en vigueur. Méthode: Il s'agit d'une revue de dossiers de patients présentant un AVCA admis à l'Hôpital Général d'Ottawa sur une période de six mois. L'utilisation de médicaments antihypertenseurs (type, dose, voie d'administration, lectures de tension artérielle (TA)) pendant les sept premiers jours après l'admission ont été relevés. Résultats: La nitroglycérine administrée par voie transdermique était l'agent antihypertenseur le plus souvent utilisé. Alors que la baisse de la TA recommandée chez les patients hypertendus présentant un AVCAischémique est de $15 \%$ sur 24 heures, la nitroglycérine a causé une baisse de plus de $15 \%$ de la TA sur 24 heures dans $60 \%$ des cas où elle a été utilisée. De plus, malgré les préoccupations quant à l'utilisation de la nifédipine sublinguale, c'était le deuxième agent le plus souvent prescrit. Il était étonnant de constater que l'intervalle moyen entre la première lecture de TA suivant le début de la médication antihypertensive était de $117 \pm 43$ minutes dans l'AVC ischémique et de $88 \pm 89$ minutes dans l'AVC hémorragique. Conclusions: Les lignes directrices actuelles pour la prise en charge de l'hypertension post AVCA semblent avoir peu d'influence sur le mode de prescription, ce qui entraîne des variations considérables dans la pratique. De telles variations, probablement dues à l'incertitude causée par le manque de données provenant d'études contrôlées randomisées, sont intolérables parce que les patients peuvent être soumis à des soins non standardisés potentiellement nocifs tels des choix inappropriés d'agents antihypertenseurs et une surveillance inadéquate de la TAcomme on l'a observé dans cette étude.

Can. J. Neurol. Sci. 2002; 29: 125-131

Acute hypertension is observed in approximately $80 \%$ of patients with acute stroke. ${ }^{1,2,3}$ Average systolic blood pressure (SBP) and diastolic blood pressure (DBP) can rise 20 and 10 $\mathrm{mmHg}$ respectively, during the first ten days following a stroke. ${ }^{4}$ The mechanism underlying this acute elevation of blood pressure (BP) appears to be multifactorial, and includes rise in plasma catecholamines, increased sympathetic discharge, as well as activation of the renin-angiotensin and adrenocorticotrophic/ cortisol systems, among others. ${ }^{5}$ Although BP elevation in acute stroke is thought useful in the maintenance of cerebral perfusion pressure and encouragement of collateral blood flow into the ischemic penumbra, observations have been made linking early hypertension with poor outcome assessed as death, dependence or disability. ${ }^{5-7}$ However, other studies have argued against such an association. ${ }^{8}$

From the Department of Pharmacy (SK, CC) and Division of Neurology, (AGD), The Ottawa Hospital - General Campus, University of Ottawa, Ottawa, ON Canada. ReCEIVED March 13, 2001. ACCEPTED INFINALFORM OCTOBER 5, 2001.

Reprint requests to: Andre G. Douen, Division of Neurology, The Ottawa Hospital, General Campus, 501 Smyth Rd., Ottawa, ON K1H 8L6 Canada. 
Situations that clearly necessitate treatment of hypertension during an acute stroke include the need for thrombolytic therapy, and life threatening end organ damage such as concurrent myocardial infarction, hypertensive encephalopathy, aortic dissection, renal failure secondary to accelerated hypertension, or intraparenchymal hemorrhage. ${ }^{1,4,9}$ Furthermore, while elevated BP might assist cerebral perfusion pressure, a rapid increase in perfusion pressure above the upper autoregulatory limits, could result in worsening cerebral edema and hemorrhagic transformation secondary to increased microvascular pressures. ${ }^{4,5,10}$ Consequently, the goal of drug therapy in ischemic stroke should be aimed at preventing further brain injury due to excessive hypertension without compromising cerebral perfusion pressure. However, the lack of clinical trials in this area has led to discrepancies regarding the best way to manage poststroke hypertension. ${ }^{3-5,10-12}$

Although there are guidelines, based largely on expert opinion, for treatment of hypertension in acute stroke, it is unknown how well these recommendations are adopted in actual practice. We undertook a retrospective chart review to compare current recommendations ${ }^{13-18}$ with actual prescribing patterns for treatment of hypertension in acute stroke, at a large tertiary care hospital.

\section{Methods}

We conducted a retrospective observational chart review of patients admitted with a diagnosis of stroke to the Ottawa Hospital-General Campus, over six consecutive months from June 1 to November 30, 1997. Patients admitted with the primary diagnosis of acute ischemic stroke or hemorrhagic stroke over six consecutive months were identified from a stroke registry. Hemorrhagic stroke and intracerebral hemorrhage were considered to be synonymous. Data collection included documenting the type of stroke, past history of hypertension, antihypertensive medications prescribed prior to and following admission, and use of anticoagulation prior to admission. The highest and lowest daily BP readings for the first seven days following admission were recorded. Any antihypertensive agents used acutely to treat high BP, and BP before and after treatment were noted. Complications arising from treatment and failure to treat were documented. Patients were excluded if they were diagnosed with a subarachnoid hemorrhage, treated with thrombolytics, enrolled in another study, or required only palliative care. Unavailability of charts also led to exclusion from the study.

The definition of poststroke hypertension is not clearly defined in the literature. Furthermore, the lack of clinical trials in this area has led to a number of unsubstantiated opinions from individual experts and special writing groups, who base their guidelines from nonrandomized trials on weak levels of evidence. With regard to the latter, levels of evidence are usually ranked I - V, with level I and II based on randomized trials, levels III - IV are based on nonrandomized cohort studies and level $\mathrm{V}$ based on anecdotal reports. ${ }^{15,16}$ In addition, the strength of a recommendation is graded $\mathrm{A}$ to $\mathrm{C}$, with $\mathrm{A}$ being supported by level I evidence, B, supported by level II evidence, while C is supported by levels III, IV and V evidence. ${ }^{15,16}$

A review of the literature regarding guidelines for manage- ment of poststroke hypertension revealed that these guidelines are poorly supported by strong levels of evidence. One example of this is the recommendation of a 'Special Writing Group' of the Stroke Council, American Heart Association, that antihypertensive agents should be used in acute ischemic stroke for SBP $>220 \mathrm{mmHg}$ or mean arterial pressure (MAP) >130 mmHg (levels of evidence III through V, grade C). ${ }^{15}$ This expert panel did not provide recommendations for management of DBP. In contrast, other experts have opined that in acute ischemic stroke treatment should be initiated for SBP $>200 \mathrm{mmHg}^{2,17}$ and/or DBP $>120 \mathrm{mmHg} .{ }^{1,2}$ Others still have suggested that acceptable $\mathrm{BP}$ ranges in acute ischemic stroke should be SBP $160 \pm 20$ mmHg or DBP of $110 \pm 10 \mathrm{mmHg} .{ }^{13}$

With regard to hemorrhagic stroke, the 'Special Writing Group' for the American Heart Association balanced two theoretical rationales (decreasing BP decreases risk of ongoing bleeding but may also decrease cerebral perfusion pressure and worsen brain injury) to recommend the maintenance of MAP below $130 \mathrm{mmHg}$, using the weakest levels of evidence (V, grade C). ${ }^{16}$ This writing group also used similar weak levels of evidence to suggest BP treatment in hemorrhagic stroke of SBP $>180$ or DBP > 105 (level V, grade C). ${ }^{16}$ In contrast, others have suggested that BP should be lowered in the presence of intracerebral hemorrhage if SBP $>200 \mathrm{mmHg}$ or DBP $>120$ mmHg. ${ }^{1}$

It is clear that there are no concrete guidelines for management of acute poststroke hypertension. In the absence of a definitive study, we extrapolated from the existing reports, ${ }^{1,2,13,15-18}$ to identify compromise ranges in BPparameters to define poststroke hypertension as follows: SBP > $200 \mathrm{mmHg}$, DBP $>110 \mathrm{mmHg}$ (>105 mmHg for hemorrhagic stroke) or a MAP $>130 \mathrm{mmHg}$, during the first seven days of admission. Similar parameters are currently being used by one large multicentre clinical trial evaluating the efficacy of the antihypertensive agent Candesartan in acute stroke management. ${ }^{19}$ Patients were subdivided into two groups depending on whether the stroke was ischemic or hemorrhagic. The highest and lowest independent SBP, DBP, and MAP were recorded on a daily basis for the first seven days of hospital stay. If patients were treated for acute hypertension their SBP, DBP and MAP were recorded prior to and after administration of the antihypertensive agent. The drug used, together with the dose, route of administration and time to the first measured post-dose $\mathrm{BP}$ was recorded. Treatment failure was defined as failure to decrease BPbelow the defined parameters for SBP(200 $\mathrm{mmHg}$ ), DBP (110 mmHg, ischemic; $105 \mathrm{mmHg}$, hemorrhagic), MAP (130 $\mathrm{mmHg}$ ), or to within $15 \%$ (ischemic) ${ }^{17,20}$ and $20 \%$ (hemorrhagic) of initial BP over the ensuing 24 hours. ${ }^{1,21}$ By comparison, an excessive drop in BP was defined as a reduction in SBP, DBPor MAPby $>15 \%$ in ischemic strokes ${ }^{17,20}$ and $>20 \%$ in hemorrhagic ${ }^{1,21}$ strokes, within 24 hours. Although we cannot be entirely sure that an excessive drop in BP is solely due to the use of antihypertensive agents, the temporal relationship of the fall in BP to the initiation of therapy, implicates the antihypertensive agent in the excessive lowering of the BP.

Complications assessed included hypersensitivity reactions to the medication, tachycardia defined as an increase in heart rate $>20 \%$ of baseline, extension or secondary infarctions confirmed by computerized tomography of the head, and excessive drop in 
BP (defined above). We also assessed renal impairment, defined as an increase in serum creatinine greater than $40 \%$ (not due to other identifiable cause) or myocardial infarction (assessed by electocardiogram changes and elevated serum creatin kinase isoenzyme $\mathrm{MB}(\mathrm{CK}-\mathrm{MB})$ ), in order to determine if $\mathrm{BP}$ was lowered sufficiently to avoid end-organ damage. Complications secondary to failure to treat included detection of hemorrhagic transformation of ischemic stroke, renal impairment and myocardial infarction (as defined above).

\section{RESULTS}

One hundred and twenty-seven patients were admitted with a diagnosis of ischemic stroke. Of these, 18 patients were excluded from the study because of unavailability of charts from medical records (12 patients), enrolment in other studies (two patients), misclassification (two patients), and two were excluded as their therapy was documented as palliative only. Twenty-six patients were admitted with a diagnosis of hemorrhagic stroke during this period. Of these 26 patients, three charts were excluded from review because of chart unavailability (two charts) and misclassification (one chart). Patient demographics are shown in Table 1 . In the ischemic group, $55 \%$ had a prior history of hypertension compared to $48 \%$ in the hemorrhagic group.

In the ischemic stroke group $(n=109)$, the mean SBP, DBP and MAP on admission were $165 \pm 28 \mathrm{mmHg}, 89 \pm 20 \mathrm{mmHg}$ and $113 \pm 19 \mathrm{mmHg}$, respectively (Table 2). Thirty-nine of the 109 patients $(36 \%)$ had at least one reading of elevated BP that met the predefined criteria for acute poststroke hypertension (Table 3). Of those 39 patients, 28 patients (72\%) had a history of hypertension prior to admission. Eleven of these 39 patients $(28 \%)$ were treated for elevated BPa total of 29 times. The drugs used for acute intervention of BP management within the first seven days, exclusive of regular premorbid antihypertensive medications, were transdermal nitroglycerin paste, sublingual and oral nifedipine, propranolol, and captopril. The percent reduction in BPaccording to drug and time to recorded effect are shown in Table 4. The time to the recorded effect reflects the first BPmeasurement recorded by the nurse after drug administration. On average, the time for this first BP measurement for patients with ischemic stroke was $117 \pm 43$ minutes. Target SBP, DBP and MAP of $<200,110$, and $130 \mathrm{mmHg}$ respectively, were not met six of the 29 times that acutely high BP were treated. Four were treated with nitroglycerin paste, three times with the one inch dose and once with the 1.5 inch dose; once with oral nifedipine $10 \mathrm{mg}$ and the other with oral propranolol $40 \mathrm{mg}$. There was an excessive (>15\%) drop in BP within 24 hours, 15 times (twice with captopril, three times with sublingual nifedipine $10 \mathrm{mg}$, nine times with nitroglycerin paste one inch and once with nitroglycerin paste 1.5 inches) (Table 4). Antihypertensive medications were reordered within 24 hours of admission in 41 of 46 patients $(89 \%)$ who were taking these medications prior to admission. Twenty-eight patients with a history of hypertension prior to admission and having one episode of elevated BP in hospital, were restarted on their preadmission antihypertensive medications within the first 24 hours.

In patients with hemorrhagic stroke $(n=23)$, the average SBP, DBP, and MAP on admission were $167 \pm 31 \mathrm{mmHg}, 89 \pm 19$ $\mathrm{mmHg}$ and $115 \pm 21 \mathrm{mmHg}$, respectively (Table 2). Eleven of
Table 1: Patient demographics

Ischemic $(n=109) \quad$ Hemorrhagic $(n=23)$

$\begin{array}{lcc}\text { Male } & 50(46 \%) & 13(57 \%) \\ \text { Female } & 59(54 \%) & 10(43 \%) \\ \text { Mean age (years) } & 68(\text { range: } 36-94) & 75(\text { range: } 29-94) \\ \text { History of hypertension } & 60(55 \%) & 11(48 \%) \\ \begin{array}{l}\text { Number of patients with } \\ \text { antihypertensive medications }\end{array} & 46(42 \%) & 10(43 \%) \\ \text { prior to admission } & & \end{array}$

Table 2: Average BP on admission

\begin{tabular}{lcc}
\hline BPon admission & $\begin{array}{c}\text { Ischemic Stroke } \\
(\mathrm{n}=109)\end{array}$ & $\begin{array}{c}\text { Hemorrhagic Stroke } \\
(\mathrm{n}=23)\end{array}$ \\
$\mathrm{SBP}(\mathrm{mmHg})$ & 165 (range: $110-228)$ & 167 (range: $110-210)$ \\
$\mathrm{DBP}(\mathrm{mmHg})$ & 89 (range: $50-143)$ & 89 (range: $60-140)$ \\
MAP $(\mathrm{mmHg})$ & 113 (range: $70-168)$ & 115 (range: $78-163)$
\end{tabular}

Table 3: Patients with increased SBP, DBP, MAPwithin the first seven days of admission

\begin{tabular}{lc}
\hline & Ischemic Stroke $(\mathbf{n}=\mathbf{1 0 9})$ \\
patients with $\mathrm{SBP}>200 \mathrm{mmHg}$ & $29(27 \%)$ \\
patients with $\mathrm{DBP}>110 \mathrm{mmHg}$ & $28(26 \%)$ \\
patients with MAP>130 mmHg & $31(28 \%)$ \\
patients with at least one elevated reading & $39(36 \%)$ \\
$\begin{array}{l}\text { patients with at least one elevated reading } \\
\text { and a history of hypertension }\end{array}$ & 28 \\
& \\
& \\
patients with SBP>200 mmHg & \\
patients with DBP>105 mmHg & $7(30 \%)$ \\
patients with at least one elevated reading & $11(48 \%)$ \\
patients with at least one elevated reading & 7 \\
and a history of hypertension &
\end{tabular}

the $23(48 \%)$ met our criteria for poststroke hypertension (Table 3 ). Seven of these 11 patients had a history of hypertension prior to admission. Three of the 11 patients $(27 \%)$ with elevated BPin hospital were treated for acute hypertension 24 times. The drugs used were nitroglycerin paste, metoprolol, sublingual nifedipine, and intravenous labetalol. The percent reduction in BP for each drug and the time to the lowest recorded BP after treatment are tabulated in Table 5. The average time for first BP measurement in patients with hemorrhagic stroke was $88 \pm 89$ minutes. There were seven treatment failures in total, three attributed to nitroglycerin paste one inch, three to nitroglycerin paste two 
Table 4: Percent reduction in BP for each drug and time to lowest BP in patients with ischemic stroke treated for acute poststroke hypertension

\begin{tabular}{|c|c|c|c|c|c|c|c|c|}
\hline \multirow{2}{*}{\multicolumn{2}{|c|}{$\begin{array}{l}\text { number of patients } \\
\text { treated }(\mathbf{n = 1 1})^{*}\end{array}$}} & \multirow[t]{2}{*}{$\begin{array}{l}\text { number of } \\
\text { times used }\end{array}$} & \multicolumn{3}{|c|}{$\begin{array}{c}\% \text { reduction } \\
(\text { mean })\end{array}$} & \multirow[t]{2}{*}{$\begin{array}{l}\text { time to recorded } \\
\text { effect }(\mathrm{min})\end{array}$} & \multirow[t]{2}{*}{$\begin{array}{l}\text { number of times } \\
\text { target BP not reached }\end{array}$} & \multirow[t]{2}{*}{$\begin{array}{c}\text { drop in } \\
\text { BP> }>15 \% * * *\end{array}$} \\
\hline & & & SBP & DBP & MAP & & & \\
\hline captopril $6.25 \mathrm{mg}$ po & 2 & 2 & 5 & 16.1 & 11 & 90 & 0 & 2 \\
\hline nifedipine $10 \mathrm{mg}$ po & 1 & 1 & 0 & 0 & 0 & 120 & 1 & 0 \\
\hline nifedipine $10 \mathrm{mg} \mathrm{sl}$ & 4 & 6 & 15.8 & 10.6 & 13.3 & 136 & 0 & 3 \\
\hline nitropaste $1.5^{\prime \prime}$ & 2 & 2 & 24.7 & 25.8 & 25.2 & 185 & 1 & 1 \\
\hline propranolol $40 \mathrm{mg}$ po & 1 & 1 & -2.9 & 4.6 & 1.5 & 140 & 1 & 0 \\
\hline
\end{tabular}

* Some patients used more than one agent.

** Target BPfor ischemic stroke is MAP $<130 \mathrm{mmHg}, \mathrm{SBP}<200 \mathrm{mmHg}, \mathrm{DBP}<110 \mathrm{mmHg}$.

*** Excessive drop in BPfor ischemic stroke considered to be $>15 \%$ within 24 hours.

Table 5: Percent reduction in BP for each drug and time to lowest BP in patients with hemorrhagic stroke treated for acute poststroke hypertension

\begin{tabular}{|c|c|c|c|c|c|c|c|c|}
\hline & \multirow[t]{2}{*}{$\begin{array}{l}\text { number of patients } \\
\text { treated }(n=3) *\end{array}$} & \multirow[t]{2}{*}{$\begin{array}{l}\text { number of } \\
\text { times used }\end{array}$} & \multicolumn{3}{|c|}{$\begin{array}{c}\% \text { reduction } \\
\text { (mean) }\end{array}$} & \multirow[t]{2}{*}{$\begin{array}{l}\text { time to recorded } \\
\text { effect (min) }\end{array}$} & \multirow[t]{2}{*}{$\begin{array}{c}\text { number of times } \\
\text { target BPnot reached } * *\end{array}$} & \multirow[t]{2}{*}{$\begin{array}{c}\text { drop in } \\
\text { BP> } 20 \% * * *\end{array}$} \\
\hline & & & SBP & DBP & MAP & & & \\
\hline labetalol infusion & 1 & 1 & 45 & 41.7 & 43.5 & 20 & 0 & 1 \\
\hline metoprolol 5 mg IV & 1 & 2 & 10.9 & 16.1 & 13.7 & 40 & 1 & 1 \\
\hline nifedipine $10 \mathrm{mg}$ sl & 1 & 4 & 20.3 & 20.1 & 20.4 & 81 & 0 & 3 \\
\hline nitropaste $1 "$ & 2 & 9 & 9.7 & 12 & 11 & 256 & 3 & 2 \\
\hline nitropaste $2 "$ & 1 & 8 & 10.2 & 3.3 & 6.8 & 43.8 & 3 & 1 \\
\hline
\end{tabular}

* Some patients used more than one agent.

** Target BPfor hemorrhagic stroke is MAP $<130 \mathrm{mmHg}, \mathrm{SBP}<200 \mathrm{mmHg}, \mathrm{DBP}<105 \mathrm{mmHg}$.

*** Excessive drop in BPfor hemorrhagic stroke considered to be $>20 \%$ within 24 hours.

inches, and one to metoprolol. Excessive reduction in BP occurred eight times and three of these were attributed to sublingual nifedipine $10 \mathrm{mg}$, two to nitroglycerin paste one inch, and one each to nitroglycerin paste two inches, intravenous metoprolol and intravenous labetalol. Antihypertensive medications were reinitiated on the first day of hospital stay in eight of nine $(89 \%)$ patients taking medications prior to admission.

In this small study, no acute complications were observed in treated or untreated groups, apart from asymptomatic excessive drop in BP $>15 \%$ (ischemic stroke) or $>20 \%$ (hemorrhagic stroke) observed in a small number of cases. However, the full impact of treatment of hypertension in acute stroke can only be accurately assessed through prospective randomised studies with appropriate sample size.

\section{Discussion}

The relative dearth of clinical trials addressing patient outcome following management of elevated BP in acute stroke has led to considerable controversy and reliance on recommendations based largely on expert opinion. A review of the current literature suggests different thresholds for treatment of hypertension following both ischemic and hemorrhagic strokes. ${ }^{9-}$ ${ }^{18}$ It has been previously suggested that treatment of elevated BP in ischemic strokes is only warranted if MAP is $>130 \mathrm{mmHg}$ or SBP > $220 \mathrm{mmHg}$, or DBP>120 mmHg (Levels of Evidence III through IV). ${ }^{16}$ While these recommendations were upheld more recently in the National Institute of Neurological Disorders and Stroke (NINDS) guidelines for treatment of hypertension in acute stroke, ${ }^{22}$ others have advocated lower thresholds for treatment, SBP > $200 \mathrm{mmHg},{ }^{2,17}$ and others still have suggested 
that a SBP of $160 \pm 20 \mathrm{mmHg}$, and DBP of $110 \pm 10 \mathrm{mmHg}$ would be acceptable ranges during acute ischemic stroke. ${ }^{13}$ However, the decision to lower BPduring an acute stroke may be warranted even below these suggested parameters if there is evidence of end organ damage.,11,12,14 A $15 \%$ or less reduction of BPhas been suggested during the first 24 hours, ${ }^{17}$ consistent with the observation that in ischemic stroke, a $>16 \%$ decrease in SBP from baseline over a 24 hour period results in decreased cerebral blood flow to the affected area. ${ }^{20}$

On the other hand, The Sixth Report of the Joint National Committee on Prevention, Detection, Evaluation, and Treatment of High Blood Pressure (JNC-VI) ${ }^{14}$ does not provide specific parameters and only suggests that in ischemic stroke, it is appropriate to withhold treatment unless BP is very high. The JNC-VI does, however, recommend maintenance of SBP and DBP below $180 \mathrm{mmHg}$ and $105 \mathrm{mmHg}$, respectively, if treatment with thrombolytics is indicated, consistent with the NINDS randomised study on the use of recombinant tissue plasminogen activator (rtPA) in acute stroke. ${ }^{22}$ However, it is unclear how guidelines were established in the latter study. Although specific treatment was not clearly defined in the NINDS rtPA study protocol, agents used to achieve target BP of less than $185 \mathrm{mmHg}$ systolic and $110 \mathrm{mmHg}$ diastolic were thought to include administration of intravenous nitroprusside, or repeated doses of labetalol, enalaprilat and sublingual nifedipine. ${ }^{18}$ Consequently, because antihypertensive therapy was not clearly decided upon a priori in the NINDS rtPA trial, there is little useful information about the management of stroke patients that can be derived from this study. Moreover, patients who received acute antihypertensive treatment postthrombolysis had worse outcomes than those who did not. ${ }^{23}$ The latter might indicate that specific thresholds exist for BP lowering in acute stroke, as previously suggested. ${ }^{20}$

The management of acute hypertension in hemorrhagic stroke is somewhat more complex, since the treatment of hypertension in hemorrhagic stroke depends on a number of factors including (i) the underlying mechanism, e.g. aneurysmal rupture versus hypertensive hemorrhage; (ii) the need to maintain adequate perfusion pressure and to prevent vasospasm (in cases of subarachnoid hemorrhages); (iii) need to control hematoma expansion and rebleeding that might result from sustained elevated BP. The JNC-VI classifies intracranial hemorrhage as a hypertensive emergency with recommendations for immediate reduction in BP (not necessarily to normal range). While this view is supported by others, ${ }^{13}$ it is not universal. ${ }^{12}$ Although it has been suggested that physical disruption and local tissue pressure caused by intraparenchymal hemorrhages produces a zone of ischemia surrounding the clot which might benefit from elevated $\mathrm{BP},{ }^{12}$ this needs to be weighed against the risk of hematoma expansion, increased risk of herniation and/or extension into ventricles. Indeed, a SBP of $\geq 200 \mathrm{mmHg}$ on admission is a predisposing factor to enlargement of a spontaneous intracerebral hematoma. ${ }^{24}$ In addition, hematoma size is directly linked to patient 30-day mortality, i.e. larger intraparenchymal hemorrhages have worse prognosis. Furthermore, recent studies in an experimental model of intracerebral hemorrhage using autologous blood injection in mongrel dogs did not show any evidence of an ischemic penumbra. ${ }^{25}$ Taken together, these studies strongly argue in favor of early BP treatment in hemorrhagic stroke to control bleeding and hence hematoma expansion. However, the natural history of the hemorrhage must always be considered and elevated blood pressures might be warranted in some circumstances e.g. risk of vasospasm in patients with subarachnoid hemorrhages. As with ischemic stroke, evidence of end-organ injury secondary to hypertension will also favor treatment of elevated BP. Consequently, management of acute hypertension in hemorrhagic strokes should be assessed carefully with particular attention to the clinical scenario and neuroimaging.

The suggested thresholds for treatment of elevated BP in acute hemorrhagic strokes are also quite varied. One source recommends intervention if $\mathrm{SBP}$ is $>200 \mathrm{mmHg}$ or DBP is $>120 \mathrm{mmHg},{ }^{1}$ while others recommend lower thresholds, SBP $>180 \mathrm{mmHg}$ or MAP> $130 \mathrm{mmHg} .{ }^{16,18}$ Furthermore, a suggested moderate reduction in $\mathrm{BP}$ of up to $20 \%$ during the first 24 hours, ${ }^{1,21}$ is contrasted by alternate recommendations for BP reduction of no more than $25 \%$ within minutes to two hours, with a suggested target SBP of $160 \mathrm{mmHg}$ and DBP of $100 \mathrm{mmHg}$ within two to six hours. ${ }^{14}$

In our study, $\sim 72 \%$ of all stroke patients, ischemic and hemorrhagic, who were hypertensive at some point during their first seven days in hospital did not receive treatment. This tendency to withhold treatment is likely due to the widely-held view that actively decreasing BPin an acute stroke will decrease cerebral perfusion pressure and could extend the area of infarction. When hypertension was treated, nitroglycerin paste was the most commonly prescribed drug. In the ischemic stroke group nitropaste induced an excessive $>15 \%$ reduction in $\mathrm{BP}$ within 24 hours $\sim 60 \%$ of times administered and did not achieve target BP on four occasions. In the hemorrhagic stroke population studied, nitroglycerin paste was used 17 times and produced a BP reduction of $>20 \%$ within 24 hours on three occasions and was ineffective in reaching target BP six times.

Although there are valid concerns regarding unpredictable decreases in BPwith sublingual nifedipine, ${ }^{20,26}$ this agent was the second most commonly prescribed first line drug. Sublingual nifedipine was used seven times in ischemic stroke and resulted in $>15 \%$ reduction $\mathrm{BP}$ on three of these seven occasions. In the hemorrhagic group studied, sublingual nifedipine was administered four times in the same patient, and on three of these occasions reduced BP by $>20 \%$ within 24 hours. The other antihypertensive medications prescribed included captopril, propranolol and oral nifedipine during ischemic stroke, and intravenous labetalol and metoprolol in hemorrhagic stroke. However, these medications were used too infrequently to comment on their effectiveness.

One important observation in this study is the length of time to first BP recording following administration of antihypertensive therapy. The average length of time was almost two hours in the ischemic group and 1.5 hours in the hemorrhagic group. This observation is indeed disturbing as it might suggest inappropriate follow-up of BP after initiation of treatment, in acutely ill stroke patients, and might reflect the lack of evidencebased guidelines in these patients. On the other hand, our study collected data on the time to first recorded BP, and did not account for unrecorded BP measurements, that might have been made at an earlier time than that recorded in the chart.

In variance to the prescribing patterns observed in this study, 
angiotensin-converting enzyme (ACE) inhibitors, which have an onset of action within minutes, duration of action of a few hours, and have been recommended as first-line therapy for the treatment of hypertensive urgencies, ${ }^{27}$ might be useful in managing acute poststroke hypertension. Captopril, which has a peak hypotensive effect within 1-2 hours, ${ }^{28}$ may be a reasonable choice. Initial doses of 12.5 to $25 \mathrm{mg}$, could be followed by a second or third dose at $0.5-1$ hour intervals if necessary. Sublingual captopril may also be an option, ${ }^{29-31}$ but no studies have demonstrated the superiority of sublingual captopril over oral administration. ${ }^{32}$ In contrast to ACE inhibitors, calcium antagonists such as nifedipine or nicardipine should be avoided because of unpredictable absorption and possible precipitous fall in $\mathrm{BP}^{20,26}$ In addition, reflex tachycardia with increased myocardial oxygen demand and peripheral vasodilation causing steal in certain vascular beds has also been attributed to calcium antagonists. ${ }^{19,20}$

Patients who do not respond to oral agents or have a MAP $\geq$ $130 \mathrm{mmHg}$ or $\mathrm{SBP} \geq 220 \mathrm{mmHg}$ may benefit from parenteral antihypertensive agents. ${ }^{14}$ Parenteral enalaprilat is an acceptable choice and does not require cardiac monitoring. It may be given $1.25 \mathrm{mg}$ IVevery six hours as needed and doses up to $5 \mathrm{mg}$ have been used. ${ }^{14}$ The onset of action is 15 to 30 minutes and the duration of action is six hours. A 50\% dose reduction is required for those with renal insufficiency or a creatinine clearance less than $0.5 \mathrm{~mL} / \mathrm{second}^{28}$ The mixed alpha and beta blocker, labetalol, which has a short half life and may be cardioprotective, ${ }^{18}$ may be a good alternative to enalaprilat as it induces a relatively mild decrease in arterial pressure. In addition, labetalol's response time is 5 to 10 minutes, with a duration of action for three to six hours. ${ }^{28}$ The dose recommended by the JNC-VI is 20 to $80 \mathrm{mg}$ IV bolus every 10 minutes to a maximum of $300 \mathrm{mg}$ or 0.5 to $2.0 \mathrm{mg}$ per minute via continuous infusion; ${ }^{14}$ cardiac and frequent BP monitoring are necessary. If these measures are ineffective, then sodium nitroprusside can be used, provided that elevated intracranial pressure is not suspected. Nitroprusside requires cardiac monitoring and thus admission to an intensive care unit. Although nitroglycerin paste has been suggested as a possible alternative in the NINDS guidelines, and is commonly used at this institution, there is no literature supporting its use in antihypertensive therapy during an acute stroke. Overall, we observed a relatively excessive reduction in $\mathrm{BP}$ in $50 \%$ of patients treated with antihypertensive agents in the ischemic group.

The treatment of acute hypertension following hemorrhagic stroke involves similar principles. Oral captopril, at similar doses suggested for ischemic strokes, may be a reasonable first choice if hypertension is considered moderate (i.e. SBP between 200 and $220 \mathrm{mmHg}$, or DBP between 110 and $120 \mathrm{mmHg}$ or MAP $\geq 130$ ). However, intravenous agents should be considered for hypertensive emergencies (situations requiring immediate BP reduction to prevent or limit end organ damage, including hypertensive encephalopathy). ${ }^{14}$ Agents which have unfavorable effects on cerebral perfusion pressure should be avoided, including hydralazine, which can cause cerebral vasodilation ${ }^{1,9}$ and clonidine and methyldopa which may depress higher cerebral functions and thus are not good choices. ${ }^{1,4}$

The observation that elevated BP spontaneously remits in the majority of patients within the first 10 days $^{1}$ has been used to argue for a conservative approach to treating hypertension in acute stroke. However, the full impact of hypertension on functional recovery is unknown. Although a review of the published literature in this area has led some to conclude that there is not enough evidence to fully evaluate the effect of altering BP after an acute stroke, ${ }^{33}$ others have reported an association between early hypertension (SBP >180 $\mathrm{mmHg}$ ) and poor outcome. ${ }^{5}$ In addition, a negative effect on functional outcome has been observed in stroke patients with markedly elevated MAP $\geq 145$ on admission. ${ }^{34}$ The latter study also reported that persistent inadequate control of BP adversely affected the prognosis in hypertensive intracerebral hemorrhage. Moreover, improved outcome in both mortality and morbidity was observed in stroke patients whose MAP was $\leq 145$ on admission or had BPcontrol such that MAPwas $\leq 125$ during the first two to six hours. Consistent with this observation, Chamorro et $\mathrm{al},{ }^{35}$ in a study of 481 patients, observed a correlation between the odds of full neurologic recovery and a 20-30\% decrease in MAP within 48 hours of an acute stroke. However, the positive findings in favour of BP management during an acute stroke is contradicted by earlier studies suggesting that higher BP on admission reduces the risk of ischemic stroke progression. ${ }^{8}$ Nevertheless, we do not truly know the extent to which untreated hypertension exacerbates microvascular injury and edema in an ischemic brain, and consequently should not assume that lack of neurologic worsening implies that elevated BPshould not be treated. Hence, we cannot rule out the possibility that thresholds exist for treatment of poststroke hypertension that may have a positive outcome.

In this study we investigated the extent to which current recommendations for management of hypertension in acute stroke influences clinical practice. In general, we found tremendous variability in prescribing practices that generally did not follow current recommendations, particularly with regard to thresholds for initiating treatment and choice of medication. Variations in practice were also reflected in the choice of antihypertensive agent. Despite the lack of support for using calcium channel blockers to reduce BP during an acute stroke ${ }^{36}$ and grave concerns surrounding adverse events from nifedipine in hypertensive emergencies, ${ }^{20,26}$ this agent was the second most commonly used antihypertensive. The most commonly used agent was trandermal nitropaste, which precipitated an undesirable drop in BP by $>15 \%$ within 24 hours $\sim 60 \%$ of the times used for treatment of hypertension in ischemic stroke. This is particularly worrisome since blood flow to the ischemic affected area is compromised as BP decreases below $16 \%$ of baseline over a 24-hour period in patients with ischemic stroke. ${ }^{20}$ Overall, the excessive decrease in BP observed in $50 \%$ of patients treated with antihypertensives may, in part, have been due to the alarming lack of documented BP recordings after initiation of antihypertensive medications.

This study shows an inconsistent, nonstandardized approach to treatment of hypertension in acute stroke and indicates that the current guidelines have little influence on prescribing patterns leading to considerable variations in practice. Such variations, undoubtedly due to uncertainty caused by lack of evidence from randomised controlled trials, are intolerable as it means that a 
substantial proportion of patients may be mismanaged. It is clear there is a need for definitive criteria for BPmanagement in acute stroke patients that can only be obtained through large pragmatic randomised trials of BP management in acute stroke. Two randomised clinical trials assessing BP lowering following acute stroke using transdermal nitroglycerin (ENOS:efficacy of nitric oxide in stroke trial), ${ }^{37}$ and candesartan cilexetil (ACCESS: acute canadersartan cilexetil evaluation in stroke survivors $)^{19}$ are currently ongoing, which will hopefully provide substantive data that will help define BPparameters and treatment in acute stroke patients.

\section{ACKNOWLEDGEMENTS}

André G. Douen was supported by an award from the Heart and Stroke Foundation of Ontario. We thank Dr. S. Venance for helpful comments and review of the manuscript.

\section{REFERENCES}

1. O'Connell JE, Gray CS. Treatment of poststroke hypertension: a practical guide. Drugs Aging 1996; 8: 408-415.

2. Oppenheimer S, Hachinski V. Complications of acute stroke. Lancet 1992; 339: 721-724.

3. Rashid PA, Bath PMW. Blood Pressure Management immediately after acute stroke. Stroke Review 2000; 4(2) 1-3.

4. Kenton EJ. Diagnosis and treatment of concomitant hypertension and stroke. J Natl Med Assoc 1995; 88: 364-368.

5. Bath PMW. Optimising homeostasis. Br Med Bull 2000; 56(2): $422-$ 435

6. Carlberg B, Asplund K, Hagg E. The prognostic value of admission blood pressure in patients with acute stroke. Stroke 1993; 24:1372-1375.

7. Robinson T, Waddington A, Ward-Close S, Taub N, Potter J. The predictive value of 24 hour compared to casual blood pressure levels on outcome following acute stroke. Cerebrovasc Dis 1997; $7: 264$.

8. Jorgensen HS, Nakayama H, Raaschou HO, et al. Effect of blood pressure and diabetes on stroke progression. Lancet 1994; 344: 156-159.

9. Phillips SJ. Pathophysiology and management of hypertension in acute ischemic stroke. Hypertension 1994; 23: 131-136.

10. Tietjen CS, Hurn PD, Ulatowski JA, Kirsch JR. Treatment modalities for hypertensive patients with intracranial pathology: options and risks. Crit Care Med 1996; 24: 311-322.

11. Goldstein LB. Should antihypertensive therapies be given to patients with acute ischemic stroke? Drug Safety 2000; 22:13-18.

12. Powers WJ. Acute hypertension after stroke: the scientific basis for treatment. Neurology 1993; 43: 461-467.

13. Kelley RE. Blood pressure management in acute stroke. J La State Med Soc 1996; 149: 485-489.

14. The sixth report of the Joint National Committee on Prevention, Evaluation and Treatment of High Blood Pressure. Arch Intern Med 1997; 157: 2413-2446.

15. Adams HP, Brott TG, Crowell RM, et al. Guidelines for the management of patients with acute ischemic stroke: a statement from a special writing group of the stroke council, American Heart Association. Stroke 1994; 25: 1901-1914.

16. Broderick JP, Adams HP, Barsan W, et al. Guidelines for management of spontaneous intracerebral hemorrhage: a statement for health care professionals from a special writing group of the Stroke Council, American Heart Association. Stroke 1999; 30:905-915.
17. Adams HP. Acute treatment of cerebral infarction. Therapy in Neurology II. 1995. American Academy of Neurology Annual Meeting. Seattle, Washington, USA. 1995.

18. Broderick JP. Guidelines for medical care and treatment of blood pressure in patients with acute stroke. In: Marler JR, Winter Jones P, Emr M, eds. Proceedings of a National Symposium on Rapid Identification and Treatment of Acute Stroke. The National Institute of Neurological Disorders and Stroke; Bethesda, Maryland: December 12-13, 1996; 63-68.

19. Acute candesartan cilexetil stroke survivor (ACCESS) study. Stroke $2001 ; 32: 584$.

20. Lisk DR, Grotta JC, Lamki LM, et al. Should hypertension be treated after acute stroke? A randomized controlled trial using single photon emission computed tomography. Arch Neurol 1993; 50: 855-862.

21. Kaneko T, Sawada T, Niimi T, et al. Lower limit of blood pressure in treatment in acute hypertensive intracranial hemorrhage (AHCH). J Cerebral Blood Flow Metab 1983;3:S51.

22. The National Institute of Neurological Disorders and Stroke rt-PA Stroke Study Group. Tissue plasminogen activator for acute ischemic stroke. N Engl J Med 1995; 333: 1581-1587.

23. Brott T, Lu M, Cothary R, et al. Hypertension and its treatment in the NINDS rt-PA Stroke Trial. Stroke 1998; 29:1504-1509.

24. Kazui S, Minematsou K, Yamamoto H, et al. Predisposing factors to enlargement of spontaneous intracerebral hematoma. Stroke. 1997; 28:2370-2375.

25. Qureshi AI, Wilson DA, Hanley DF, et al. No evidence for an ischemic penumbra in massive experimental intracerebral hemorrhage. Neurology 1999; 52:266-272.

26. Grossman E, Messerli FH, Grodzicki T, Kowey P. Should a moratorium be placed on sublingual nifedipine capsules given for hypertensive emergencies and pseudoemergencies. JAMA1996; 276: 1328-1331.

27. McKindley DS, Boucher BA. Advances in pharmacotherapy: treatment of hypertensive crisis. J Clin Pharm Ther 1994; 19: 163-180.

28. McEvoy GK, Litvak K, Welsh OH, eds. American Hospital Formulary Service Drug Information. Bethesda MD: American Society of Health-System Pharmacists; 1998.

29. Ceyhan B, Karaaslan Y, Caymaz O, et al. Comparison of sublingual captopril and sublingual nifedipine in hypertensive emergencies. Jpn J Pharmacol 1990; 52: 189-193.

30. Wu SG, Lin SL, Shiao WY, et al. Comparison of sublingual captopril, nifedipine, and prazosin in hypertensive emergencies during hemodialysis. Nephron 1993; 65: 284-287.

31. Angeli P, Chiesa M, Caregaro L, et al. Comparison of sublingual captopril and nifedipine in immediate treatment of hypertensive emergencies: a randomized, single-blind clinical trial. Arch Intern Med 1991; 151: 678-682.

32. Gales MA. Oral antihypertensives for hypertensive urgencies. Ann Pharmacother 1994; 28: 352-358.

33. Blood pressure in acute stroke collaboration (BASC). Interventions for deliberately altering blood pressure in acute stroke (Cochrane Review). In: The Cochrane Library, Oxford, Update Software, 2001.

34. Dandapani BK, Suzuki S, Kelly RE, Reyes-Iglesias Y, Duncan RC. Relationship between blood pressure and outcome in intracerebral hemorrhage. Stroke 1995; 26: 21-24.

35. Chamorro A, Vila N, Ascaso C, et al. Blood pressure and functional recovery in acute ischemic stroke. Stroke 1998; 29: 1850-1853.

36. Horn J, Limburg M. Calcium antagonist for acute ischemic stroke (Cochrane Review). In: the Cochrane Library, Oxford: Update Software. Issue 2, 2001.

37. ENOS Investigators, Philip Bath. Efficacy of nitric oxide in stroke (ENOS) trial. Stroke 2000; 31:2885 